\title{
Multi-agent modeling for water policy impact assessment: a road map
}

\author{
MAZZEGA, Pierre ${ }^{1,2}$ \\ SANT'ANA, Daniel ${ }^{3}$ \\ ${ }^{1}$ IJL Observatory of Environmental Changes, IRD / University of Brasilia, Brasilia, Brazil. \\ ${ }^{2}$ Geosciences Environment Toulouse, IRD / CNRS / University of Toulouse, France. pierre.mazzega@ird.fr \\ ${ }^{3}$ Environmental Control Laboratory, Faculty of Architecture and Urbanism, University of Brasilia, Brazil. dsantana@unb.br
}

\section{Resumo}

Politicas públicas de água têm grande influência sobre diferentes tipos de recursos (recursos hídricos, da terra e do solo; infraestrutura e instalações prediais; recursos financeiros; informação e conhecimento ambiental; etc.). Elas atuam sobre agentes individuais ou coletivos (usuários, gestores, empresas públicas ou privadas, associações, etc.), assim como como regras e normas de comportamento que estes atores são os destinatários ou agentes. Sistemas complexos, se for o caso, essas políticas têm vários tipos de efeitos, esperados e inesperados, os efeitos diretos e indiretos, sociais, econômicos, ambientais e eco-sistêmica. $\mathrm{O}$ atual desenvolvimento de plataformas multi-agente abre uma nova área para a definição, concepção, implementação e monitoramento da gestão da água, produzindo simulações ex ante do impacto das medidas que promovem políticas públicas de água e da evolução provável da situação sócio-HYDROSYSTEM em causa. Aqui vamos dar uma visão geral das novas oportunidades de modelagem de política da água e avaliação de impacto, que resumem as etapas do processo de modelagem e apresentar os principais ingredientes que entram na composição de uma plataforma dedicada a simulações de impacto. Também argumentam que o interesse de construir cenários de água e produção de indicadores úteis para a tomada de decisão sobre o uso, distribuição e gestão dos recursos hídricos à escala da bacia.

Palavras-Chave: Política da água, modelagem, avaliação de impacto, multi-agentes, cenário, indicadores para a tomada de decisões

\begin{abstract}
Water policies have a great impact upon different types of resources (water, land and soil resources; infrastructure and facilities; financial resources; environmental knowledge and information; etc.). They involve many individual or collective actors (users, managers, public or private companies, associations, etc.) as well as rules and norms of behavior that these actors are the recipients or agents. Complex systems, if any, these policies have several kinds of effects, expected and unexpected, direct and indirect effects, societal, economic, environmental and eco-systemic. The current development of multi-agent platforms opens up a new area for the definition, design, implementation and monitoring of water management by producing ex ante simulations of the impact of measures that promote water public policies and of the likely evolution of the socio-hydrosystem concerned. Here we give a quick overview of these new opportunities of water policy modeling and impact assessment. We summarize the steps of the modeling process and present the main ingredients entering in the composition of a platform dedicated to impact simulations. We also argue the interest of building water scenarios and producing useful indicators for decision-making regarding the use, distribution and management of water resources at the basin-scale.
\end{abstract}

Keywords: Water policy, modeling, impact assessment, multi-agents, scenario, indicators for decision-making. 


\section{Introduction}

The analysis of public policies (e. g. Howlett and Ramesh, 2003; Hassenteufel, 2008) adopts a new perspective by considering them as complex systems (Bourcier et al., 2012.) and using a variety of concepts and tools own to transform the way they are designed, implemented and evaluated.

This is particularly relevant for "water policy" because they bind: a) actors (institutional or otherwise), resources (physical, financial, cognitive, etc.) and norms or rules given management objectives of sustainable use of resources and environments but also of the social and economic development; b) environmental and ecosystem dynamics, social and economic processes, and individual and collective behavior c) principles (possibly sanctioned by legal norms) and concrete and observable objectives following the teleological orientation of sustainable development.

The impact of water policy depends of course on their specific content, on the tools and "rules" that they promote, but also on the environmental and social context in which they are inserted (André et al., 2004). Nevertheless, there is a global dissemination of such national policies as the preservation of the resource and ensuring its availability for a variety of uses sometimes vital, are essential to the sustainable and intergenerational development of our societies.

The implementation of such water policy is intentionally directed towards the achievement of results, that is to say, direct and expected or desired outcomes. Nevertheless, it is inevitably accompanied by potentially adverse, indirect, unintended consequences (Merton, 1936; Mica et al., 2011), not least as a result of the adaptation behavior and strategies of the actors to the new conditions of resource use and management, but at the same time pursuing their own goals. These "impacts" are expressed through the change in the state of resources and with effects on societies that develop a wide range of activities using water and produce other resources (e. g. hydropower or productions agricultural) and economy.

In a society with its own multi-level organization, there is an undetermined number of possible ways to manage water resources in a specific territory. As a result there is a considerable interest in developing virtual (in silico) simulation tools for characterizing ex ante the likely evolution trends of socio-hydrosystems depending on the implemented policies or management options they advocate, and in comparing their respective advantages and disadvantages.
This approach requires the definition of hypothetical scenarios taking into account for example: various expected impacts of climate change on water resources and their availability and distribution in time (e. g. seasonal.) and space (contrasting watersheds); various possible changes in the land use and land cover partly in response to policies of urban or agricultural development; various demographic evolutions and population mobility; the implementation of new infrastructure related to water management (tanks, dams, canals for water transfer,...) or to the territorial and economic development; and so on.

The modeling of public policy is an area of active research, although recently opened, covering the examination of a wide range of issues. Indeed, the simulation of policy impacts (on which we focus here) is a specific problem alongside the use of information technology for the social computing, the policy analysis and visualization, the extraction of public opinion or the management of citizen participation, among others (see Crossroad 2010, for a broad overview on the domain; see also Mclntosh et al., 2007, and the website of the project MAELIA ${ }^{1}$ focused on low-water management).

\section{Why Multi-agent modeling?}

At this point it seems useful to justify a methodological and technological choice: the use of multi-agent systems. In fact, the simulation platforms that we need to develop for the impact assessment of water policy (hereinafter WPIA) are "hybrid" in that they combine both models or components based on algebraic and differential equations (used mainly for the representation of hydrological, environmental and ecosystem dynamics, or of certain economic dynamics - e. g. Cai et al., 2006; Reynaud and Leenhardt, 2008), cellular automata using simple rules (e. g. to capture the land use and land cover changes in a given territory over a few decades - cf. e. g. Piyathamrongchai and Batty, 2007), geographical information systems to collect heterogeneous information or data layers (collected from various agencies or operators) and set them in compatible forms, and proper multi-agent modules.

Multi-agent models or systems (e. g. Treuil et al., 2008) have been used for twenty years (Epstein and Axtell, 1996) to capture such complex collective phenomena emerging from the self-organization of a multitude of individual behavior based on (relatively) simple rules (see Gilbert, 2010; Tesfatsion and Judd, 2006). Several sites and

1 http://maelia1a.wordpress.com/ 
newspapers are publishing the pioneering work in the field².

What is of particular interest for the modeling of public policy is that the multi-agent approach especially (but not only) allows representing the behavior, activities and adaptive strategic calculations of actors or groups of actors (which implies the corresponding virtual agents are endowed with a model of rationality, even rough). Conventional equation-based models are not adapted to take into account the mechanisms of decision-making and coordination of actors, or to include these actors' representations of the ecosystem and societal dynamics or the knowledge they have of their environment and that they mobilize to conduct their activities.

Two principal objectives and therefore two main modes of use of multi-agents for the management of water systems are being developed: a) the companion modeling, b) and more recently modeling for the operational management of resources. Companion modeling (Etienne, 2011; Becu et al., 2008; Moglia et al., 2008) often responds to an immediate need for justification, legitimation and implementation of best practices shared among local actors of a given socio-hydrosystem based on understanding the impacts of each actor's actions on the resource and, as a result, on the activities of the other actors.

For the operational management of resources conducted under the responsibility of agencies or public bodies missioned for this purpose, the incentive is rather to develop sustainable platforms whose various modeling modules can be improved during the time, completed to add additional processes, or enriched with the acquisition of new data (survey and census data, new satellite missions and new sensors - eg SMOS $^{3}$ for the survey of the soil moisture, Megha-Tropiques ${ }^{4}$ for fields rain, SWOT $^{5}$ for the altimetry of large inland water surfaces, etc.). This type of platform or "model" is also designed to take into account the possible creation of new institutions and rules of resource management as is currently the case for example in France with the creation of unique management agencies that will take in charge the and allocation of authorized water volumes for irrigated agriculture (Lafitte et al., 2008).

2 For example: GIS and Multi-agents : http//hww.gisagents.blogspot.com/;Joumal: http///asss.soc.surrey.ac.uk/;OpenAgent-Based Modeling Consortium http:/hwww.openabm.org/

3 http://smsc.cnes.fr/SMOS/index.htm

4 http://smsc.cnes.fr/MEGHAT/index.htm

5 http://smsc.cnes.fr/SWOT/index.htm

\section{Steps in developing a WPIA simula- tion platform}

The project of developing a WPIA platform brings together researchers and students from different scientific cultures, who agree to share knowledge and to design, implement and evaluate a common simulation tool. Completing this "contract" presents all the challenges of the interdisciplinary production of new knowledge (e. g. possible distrust between disciplines, low valuation of interdisciplinary knowledge production in individual evaluations, etc.) that we will not discuss here, considering only the operational aspects of such project.

The platform intends to contribute to solving a specific problem. The precise identification of the latter is important because it involves the definition of the objectives shared by members of the project and it limits the objects and processes to consider during modeling. Then place the problem as an issue to be resolved or more precisely as a question provides the opportunity for each discipline to provide contributions that make sense in their own specialized field of research and the relevance of which is explicitly justified. Each proposed contribution also induces a relative positioning of the other contributions and leads to a coherent design and development plan of the simulation tool. The selection of the main outlines of the scenarios that are of interest for the development and management of water and territories, can engage in this first step.

Each research field does not necessarily give the same meaning to the terms of a nevertheless largely used lexicon: resource, actor, environment, norms, common good and heritage, scenario, model, etc. have different acceptances, connotations and ontological insertions, depending on the disciplinary context. The pooling and approval of a minimum vocabulary avoid that misinterpretations and misunderstandings do persist within the project. This lexicon or glossary can possibly mention some other more disciplinary uses of certain ter$\mathrm{ms}^{6}$ so that everyone is informed. It may take the form of a more complete (contribution to an) ontology which gives a view of the first level of formalization of the linkages between the concepts solicited to resolve the question at hand.

Following our experience, the use of a participatory method of construction of the design and ingredients of the simulation platform is essential. For example, the method named "ARDI" (for "Actor - Resources - Dynamic - Interactions", Etienne et al., 2008) is valuable: it leads not only

$6 \quad$ For example glossaries are commonly attached to legal texts. 
to share everyone's relevant views and knowledge, but also to organize that knowledge in a hierarchy of decreasing importance to the project objectives and hence to justify collectively the necessary choices to be made to simplify the representations embedded in the platform (at least by provision: some entities and processes initially discarded can be reintroduced later). However the dynamics of the workshops of participative building of the platform is always guided by the constant desire to achieve the objectives of the project (preventing from being lost in the complexity of the reference socio-hydrosystem).

The knowledge produced collectively should benefit from an easy-to-use support of representation based on a well-founded semantic. For example, the platform can be decomposed into a series of structural and behavioral diagrams according to the conventions of UML (for "Unified Modeling Language"; OMG 2005, 2010), in particular:

1. Class diagram: static representation of the system to be developed, focusing on the concepts of class (and object) and association;

2. Activity diagram (or process) the internal representation of the behavior of simulated operations or use case, based on the concepts of node bifurcation junction and fusion, input / output stream object and sheet;

3. Interaction Diagrams: represents the flow of control and interactions between entities.

Examples of diagrams are available on the website of the MAELIA project impact management of low-flow simulation (see foot-note 1). Note that the process of decision making is also represented by activity diagrams. These diagrams are regularly discussed and amended at the workshops of participatory modeling. They help checking the consistency between the various entities and processes in the model (consistency of entities' existence, of space and time scales of the variables, of integrity constraints, etc.), the availability of required data and the articulation of information flows throughout the platform.

Each module is then developed in the form of computer codes (with inputs and outputs, impacts on state variables, compatibility constraints such as process synchronization and compatibility scales, and using one or more computer languages) in an environment of development (e. g. the GAMA development environment for spatially explicit agent-based modeling and simulation, the NetLogo multi-agent programmable modeling environment, the REPAST agent-based modeling toolkit, among others) with various user-friendly man-machine interaction tools: display panels (parameter values of each simulation, curves and maps produced and evolving over time), controls of digital experience, information archiving and re-addressing systems.

Some modules must then be calibrated (see Sec. 5) prior to the simulation of predefined scenarios and the production of specific indicators to assist decision makers on options for resource management (see Sec. 6).

\section{Ingredients of a WPIA simulation platform}

The specific ingredients gathered in a WPIA simulation platform depend on the question treated. However, the main classes of ingredients are (once the problem clearly defined):

\section{Common lexicon or glossary;}

2. Diagrams for the development of the platform;

3. Computer simulation codes simulating the retained processes and interactions;

4. Database;

5. Environment for the development and integration of codes, their use and handling;

6. Resources or calculations and simulations;

7. Updated documentation ensuring the transferability of codes and their use.

To clarify the ideas Table 1 lists the main processes - ecological or environmental, socio-economic, and "activities" - modeled in the simulation platform of the impact of low-water management (MAELIA Project, cf. supra; points 3, 4 and 5 of the above list).

These processes can be considered as internal or external: the internal processes act on the state variables of the platform also modified by other processes represented in the platform; the course of the external processes is not changed by the evolution of internal variables. Paradigms of representation can be deterministic, stochastic or mixed, expressed in the form of equations or transformation rules expressed in various granularities (single rule or set of rules), and at different levels of abstraction.

These choices of resolution scales are guided by the ultimate goals of the platform development 
and thus by the time horizon considered over which the scenarios will be simulated. For example, following the principle of parsimony, only the net results of some "fast" process (e. g. with correlation time of a few hours) are to be considered for simulations of decadal trends, without entering the detailed description of such process dynamics. The spectrum of the modeled process (and of those who are excluded) depends also on the question at hand. Some processes can then be represented in a more accomplished way. For example, if the problem requires a joint analysis of urban water uses, operation of the sanitation services and territorial planning, several processes will be added to the platform to link basin-scale water management to urban and peri-urban water management.

Among the processes, those related to decision-making occupy a special place because they assume a particular structure of virtual agents. However we need to separate two types of decisions: some decisions follow the predefined pattern of an unambiguous procedure whose outcome can be calculated simply on the basis of information about a set of state variables of the socio hydrosystem. "Actors" involved behave - at least theoretically, even as settled by legislation - as a kind of automata (except that in addition they take responsibility for these decisions with regard to the other actors). For example, it is normally the case for decision on the publication of restrictions on water use during droughts (in France) and for the choice of the degree of severity of the restriction decree.

"Normally" only because in real situations some consideration of the social acceptability of such a decision may be taken into account and modify the content of the decree restricting.

Other decisions take into consideration the state of resources, but also preferences, beliefs and goals of the stakeholders or "actors". It may be necessary to use one or several models of bounded

Table 1: Main processes modeled for the impact assessment of low-water management policy (* indicates an external-process; the hydrographic zone $\mathrm{ZH}$ and water management unit WMU are defined and identified in the French water management system).

\begin{tabular}{|c|c|}
\hline Process Name & Space / Time Resolution \\
\hline Hydrology (water cycle) & $\mathrm{HZ} /$ day \\
\hline Land cover dynamics* & $\mathrm{HZ} /$ year \\
\hline Urban sprawl ${ }^{*}$ & $\mathrm{HZ} /$ year \\
\hline Demography* & Municipality / year \\
\hline Agricultural demography & Municipality / year \\
\hline Meteorology: rainfall, temperature* & $\mathrm{HZ} /$ day \\
\hline Drinking water consumption & $\mathrm{HZ} /$ day \\
\hline Industrial water consumption & HZ / day \\
\hline Agricultural irrigation & HZ / day \\
\hline Municipal wastewater discharge & $\mathrm{HZ} /$ day \\
\hline Industrial wastewater discharge & $\mathrm{HZ} /$ day \\
\hline Storing water in dams & $\mathrm{HZ} /$ day \\
\hline Water releases of dams to support low water & $\mathrm{HZ} /$ day \\
\hline Growth of agricultural crops & Agricultural parcel / day \\
\hline Agricultural sowing & Agricultural parcel / day \\
\hline Agricultural harvesting & Agricultural parcel / day \\
\hline Choice of agricultural cropping & Agricultural parcel / year \\
\hline Diffusion of technical changes impacting the efficiency of water uses & Farm / year \\
\hline Purchase and sale of agricultural land & Farm / year \\
\hline Changes in the pricing of raw water* & Basin / year \\
\hline Changes in the pricing of drinking water ${ }^{\star}$ & Basin / year \\
\hline Changes in prices of agricultural inputs* & Basin / year \\
\hline Changes in prices of agricultural products* & Basin / year \\
\hline Changes in annual premiums to farmers* & Basin / year \\
\hline Water police controls and verbalization & Basin / day \\
\hline Enactment of decrees restricting water use & WMU / day \\
\hline Allocation of water volumes for irrigation* & $\begin{array}{l}\text { WMU / year [Single } \\
\text { Organization; France) }\end{array}$ \\
\hline
\end{tabular}

Fonte: MAELIA project http://maelia1a.wordpress.com/ 
rationality (Gigerenzer and Selten, 2001) to go into this level of description (documented on the basis of surveys on the stakeholders behaviors) for key actors if their decision has a significant - or even major - impact on the evolution of the socio-hydrosystem. In the case of low water management in France, virtual farmers of the MAELIA platform are endowed with a model of rationality (Taillandier et al., 2012) that allows to reproduce quite accurately the decisions on planting dates and harvesting, irrigation and crop rotation choices, activities that have a significant impact on water resources.

Virtual simulations are using data from various types: parameter values, maps, time series, simple useful information defining constraints for the design of the platform or the evolution of the state variables, etc. Table 2 gives an indicative list (not exhaustive) of data used for example in the platform of low-management management impact assessment.

Table 2: Short list of data type used for water management impact assessment modeling

\section{Data type}

\section{Administrative boundaries}

Land Parcel Identification and uses

Land use -land cover maps

Spatial demographic data \& scenario

Map of water restriction use decrees

Authorized abstraction water volumes

Digital terrain model

Soil map

Maps of rainfall \& atmospheric temperature (observation and climate scenarios)

Hydrological layers (water courses and bodies, dams, groundwater, humid zones, etc.)

Water withdrawals and rejections (agricultural, domestic, industry)

Various prices and tariffs

Determinants of decision-making (actor and activity dependent

Etc.

Fonte: MAELIA project http://maelia1a.wordpress.com/

The data sources being diverse and their linkage through a simulation platform not being the original incentive for their acquisition, these data are generally not directly compatible (different spatial or temporal resolutions, inconsistent definitions, etc.). These problems can often be avoided by making assumptions and developing computer routines allowing their simultaneous use following an explicit logical reasoning. For example we have annual data on volumes of water withdrawn from an area (for example with the resolution of the municipal territory) without knowing the exact locations of these withdrawals - and thus what water bodies effectively are concerned. Simple rules can be formulated that bind volumes collected at specific water bodies ${ }^{7}$ according to the type of use and the local physical geography.

Among the essential ingredients for the sustainability of a simulation tool, the documentation describes each element of the platform and maintains this description throughout the amendment process and enrichment of the platform. The documentation may also include a description of the conditions of numerical simulation experiment scenarios from which the simulation results ("data" of re-addressable outputs and subject to post-treatment and comparisons).

\section{Simulations, sensitivity analysis and calibration}

As will be seen in the next section a numerical experiment simulates the impacts of a given scenario. Each experience of simulation produces a "model trajectory" that is the set of values taken by all state variables (attributes) of entities of the platform throughout the simulated time period. The production of a trajectory requires an unambiguous specification of the values of all parameters of the algorithms, of the initial and limit conditions and of the data used for the simulated time period (representing in particular the forcing by the external processes: space-time distribution of rainfall, evolving market prices, see Table 1). Depending on the space and time resolution of the processes and on the number of virtual agents, the full description of the states of the platform entities at a given time can have several thousands or millions of variables.

According to the choice of parameters values of the various modules and algorithms used in the platform, the simulated trajectories are qualitatively ${ }^{8}$ different. The calibration process is to find the parameters that allow to best fit a set of data on the observed past evolution (of state variables) of the socio-hydrosystem. Distance between a simulated trajectory and the available data is a reliable criterion for estimating quantitatively the performance

$7 \quad$ Thus, the platform will also be used to define the missing data, their nature and characteristics (resolution, distribution, accuracy, frequency, etc.).

8 For nonlinear dynamic, trajectories can be also qualitatively different if a change of parameters values induces a bifurcation (e. g. Lasota and Mackey, 1994). 
of the simulation: the distance is zero if the simulation accurately reproduces all observations. The more the trajectory is away from the data, the greater is the distance. The constraints for a simulated trajectory to be acceptable are relaxed when the data are inaccurate.

This notion of distance can be refined in particular by: a) considering several "distances", each corresponding to a particular goodness-of-fit criterion (for example if a partition data into separate groups is desirable - e. g. in situ data versus satellite data, environmental data versus socio-economic data, etc.); b) over-weighting the data for certain periods of time or during the occurrence of particular events which we want to better represent in priority; c) taking into account the knowledge we have about the characteristics of errors associated with the empirical data but also with the process representations (using non-Euclidean metric). In other words the criteria for acceptability of a trajectory are designed in close relation with the objectives of the simulation and impact analysis and with the knowledge we have acquired on the observations of the socio hydrosystem and on the limits of our representation of the involved dynamics.

Before calibration - process by process (e. g. in the hydrological modules) or of all processes integrated in the platform at a time - it is necessary to perform a sensitivity analysis that identifies the parameters whose perturbation alters the trajectory of such that the distance to empirical data is significantly altered. The calibration is then carried out only on the subset of the parameters that has a detectable signature by comparison with available observations. Those parameters, whose perturbation impact is not detectable with the available data, are set to standard values to perform all simulations. Note that it is often desirable to perturb as well the initial conditions, boundary conditions or forcing data within the bounds of their estimated accuracy (what is rather called data assimilation techniques) in order to estimate the associated sensitivity of the simulations.

Many studies exist on the techniques of sensitivity analysis, calibration and data assimilation, especially in the field of environmental science using models of coupled ordinary or partial differential equations. The application of such technics to multi-agent models or hybrid platforms is in its infancy, mainly because of the complexity of nested nonlinear dynamic they represent and simulate.

Prior to the release of any results, it must be made a critical analysis of the results, of their credibility, robustness, reliability and dependence with regard to certain working assumptions (including with respect to the simplification of the socio-hydrosystem as encoded in the computer). This step requires an intensive exploration of the space of trajectories of evolution that can be simulated, and rigorous and critical comparisons with available data.

\section{Scenarios and Indicators}

Many changing factors affect the evolution of a socio-hydrosystem. Once the key factors identified in the study area, they are ranked by decreasing importance with regard to the issue addressed. Table 3 lists a few of the major factors of change considered for the basin-scale management of water in France (March et al., 2012). Other factors can be analyzed in a project that would also include the management of demand and supply in urban water (water supply, sewerage, rain-water harvesting, etc.), the development of sanitation services and water infrastructures (e. g. Alcamo and Henrich, 2008; Christian-Smith et al., 2012; Haasnoot et al., 2011; Makropoulos et al., 2008).

Table 3: Some likely factors of change in water management

\section{Evolution of water Policy and Laws}

Climate change

Creation of water resources

Evolution of agricultural Policy and Laws

Water market

Agricultural market

Demography

Hydroelectric development

Water technology innovation

Prices of agricultural inputs

Evolution of production systems

Etc.

Other factors are taken into account in the simulations of policy impacts and their assessment. Change in legal, administrative or organizational devices these policies put in place and organize is commonly one of the first factors to take into consideration (actually a set of factors which relevant components must be identified).

A scenario describes all characteristics of change of a particular factor (and therefore of the processes that it entails), considering all other things being equal. This change induces various 
modifications on the evolution of the variables describing the state of entities of the socio-hydrosystem. The trajectory generated under this scenario is compared with the trajectory corresponding to a baseline scenario (called business-as-usual scenario). It is produced by a simple extrapolation into the future of the evolution trends empirically observed on a past period.

For example, the rate of population growth (which has a direct effect on demand and water consumption) is maintained in the future to its value observed the last ten years (at the scale of the watershed, water management unit or municipality, etc.), as well as the ten-year trend of price changes (water, services, agricultural prices, etc.), the rate of transformation of land use and land cover, the trends of change of precipitation rate and surface temperature related to climate change (with impacts on the water cycle, plant growth, agricultural productivity), etc. Typically other scenarios differs from the business-as-usual scenario by changing, for example: a) the impacts of climate change on the seasonal distribution and volumes of precipitations; $b$ ) rates of change in land use and land cover (which have an impact on the water cycle at various scales); c) the modes of resource management; d) assumptions on those technological developments potentially able to improve water use efficiency (e. g. in agriculture) or to follow more accurately and with higher frequency the status of various water bodies over time (e. g. with satellite-born instruments), etc.

To each scenario corresponds a single set of simulation conditions and consequently, a single evolution trajectory of the simulated system variables. Considering the flow of information created by a single simulation (thousands or even millions of variables taking values over thousands of time steps throughout the simulated period), the comparison of induced impacts assuming various scenarios is not trivial. So we resort to indicators that "summarize" the most relevant and significant information. These indicators are usually balances estimated over a set of processes. They take the form of time series of aggregated variables, maps, etc., say everything that makes easier and clearer the impact assessment (indicators for decision-makers), or the analysis (indicators for developers) and control (indicators for platform-users) of the simulations.

Then the decision relative to the modes of water management or to the design and implementations of water policy relies on the comparison of their respective social, economic and environmental impacts, for which the simulation platform produces adequate indicators of trend. To clarify this point here are some examples of potentially useful indicators in the framework WPIA: a) Indicators of improvement or deterioration in the quality of water at survey stations; $b$ ) idem for monitoring stream flows to be compared to predefined thresholds; c) income trends of socio-professional categories related to the access and use of the water resources; d) development of irrigated agriculture and farm productivity; e) social acceptability of implemented measures; $f$ ) number of households with access to drinking water; g) changes in water tariffs; $h$ ) any public health indicators related to the quality of the water consumed; i) and so on.

Note that the choice of the most relevant scenarios to be simulated can be done in response to some request made at forums organized with / for the participation of stakeholders and water users. The choice of indicators and their definition is usually done with policy-makers and resource managers (waters, dams, financial resources, etc.). The definition of scenarios and indicators also always requires a close dialogue with the scientific community In order to remove many ambiguities, to ensure that the platform will provide relevant information about the issues, to firmly establish the indicative and uncertain nature of the information produced, but equally to ensure "social admissibility" of the same information. Indeed, it is essential to keep in mind that decisions on resource use, sharing, management, planning and financing belong to the political and participatory game (Huitema et al., 2009) as organized in a legal framework.

\section{Conclusion}

A new field of research is emerging that aims at producing reliable ex ante simulations of economic, societal and environmental impacts of public policies affecting directly or indirectly water resources and their uses. The realization of a simulation project for WPIA at scales of a few decades and of a large hydrological basin and / or an urban center can benefit from experiences already gained in other context, as we are proposing here with a kind of road map for research. The complexity and overlapping - in particular spatial and temporal - of heterogeneous dynamics require the development of hybrid platforms including in particular multi-agent modules particularly suitable for the representation of processes related to strategic decision-making on the basis of a bounded rationality endowing the virtual agents.

The difficulties arising in the implementation of this kind of interdisciplinary project are largely overcome by using various methodologies - ranging from the collective construction of glossaries or lexicons, to procedures of participatory 
modeling and the use of knowledge representation languages. Ironically one of the major challenges is "achieving simplification" to link $k^{10 " .}$

In terms of water management, it appears that at least four major challenges remain: 1) link quantitative dynamics with those processes affecting water quality (interactions with soil and vegetation, different kind of pollutions, bio-geochemical processes related to aquatic ecosystem dynamics, etc.); 2) link basin-scale water dynamics (including climate change effects, water uses and resource management) and the demand / supply for urban water and associated services; 3 ) adequately represent and related governance of water resources with the governance of territories; 4 ) design and develop tools producing indicators of social acceptability of new water policies or devices and accompanying measures.

\section{Acknowledgements}

This prospective work was possible on the one hand thanks to the experience gained with our colleagues in the project MAELIA (which we thank all colleagues involved) funded by the Science and Technology Foundation for Aeronautics and Space (STAE Toulouse; http://www.fondation-stae.net/) and thanks to the structure of BrazilFrance cooperation created by the University of Brasilia and the Institute of Research for Development (IRD, France) through the International Joint laboratory of "Environmental Change Observatory".

\section{References}

ALCAMO, J.; HENRICHS T. Towards guidelines for environmental scenario analysis. In: Environmental Futures: the Practice of Environmental Scenarios. J. Alcamo Ed., Elsevier, Amsterdam, 13-35, 2008.

ANDRÉ, P.; DELISLE, C. E.; J. P., REVÉRET. Environmental Assessment for Sustainable Development - Processes, Actors and Practice. 2004. Presses Intern. Polytechnique, École Polytechnique de Montréal, ISBN 2-55301138-5, Montréal (Canada), $x \mathrm{l}+511 \mathrm{p}$.

BECU, N.; NEEF, A.; SCHREINEMACHERS, P.; SANGKAPITUX, C. Participatory computer simulation to support collective decision-making: Potential and limits of stakeholder

$9 \quad$...of knowledge and representations of entities and processes.

$10 \quad$...the dynamic between them consistently and multi-scale. involvement. Land Use Policy, 25(4), 498-509. 2008.

BOURCIER, D., BOULET, R.; MAZZEGA, P. (eds.). Politiques Publiques Systèmes Complexes. Hermann, Paris (France), 2012. ISBN : 978-27056-8274-3, 290 pp.

CAI, X.; RINGLER, C.; ROSEGRANT, M. W. (2006) Modeling Water Resources Management at the Basin Level Methodology and Application to the Maipo River Basin. Res. Report 149, Intern. Food Policy Res. Institute, Washington D. C. (USA), ISBN 0-89629-152-9, 169 pp.

CHRISTIAN-SMITH, J.; HEBERGER, M.; ALLEN, L. Urban Water Demand in California to 2100: Incorporating Climate Change. Pacific Institute Rep., Oakland (USA), 2012, N. Ross and P. Luu eds., ISBN 13: 978-1-893790-41-4, 61 pp.

CROSSROAD. A participative roadmap for ICT research in electronic governance and policy modeling - State of the art analysis. 2010. D1.2, FP7-ICT-2009-4 SA Project (available on the web).

EPSTEIN, J. M.; AXTELL, R. Growing Artificial Societies - Social Science from the Bottom Up. MIT Press, Cambridge MA (USA), 1996. ISBN-13: 978-0262050531, 224 pp.

ÉTIENNE, M. Companion modelling - A Participatory Approach Supporting Sustainable Development. 2011. Quae Ed., Montpellier (France) ISBN: 978-2-7592-0922-4, $368 \mathrm{pp}$.

ETIENNE, M.; TOIT, D. Du; POLLARD S. (2008) MoGIRE: ARDI: a co-construction method for participatory modelling in natural resources management. Proc. Intern. Congress on Env. Modelling and Software (iEMSs 2008). Barcelona, Catalonia, July 2008. M. Sanchez-Marre, J. B'ejar, J. Comas, A. Rizzoli \& G. Guariso (Eds.), ISBN: 978-84-7653-074-0. Disponível em: http:// www.iemss.org/iemss2008/index.php?n=Main. Proceedings

GIGERENZER, G.; SELTEN, R. (eds.) (2001) Bounded Rationality: The Adaptive Toolbox. Dahlen Workshop Rep. MIT Press, Cambrideg (MA), ISBN 0-262-07214-9, 377 pp.

GILBERT, N. (Ed.) (2010) Computational Social Science. SAGE Publ., ISBN: 978-184-78717-18, 1664 pp.

HASSENTEUFEL, P. (2008) Sociologie Politique : I'Action Publique. Armand Colin, coll. U Sociologie, ISBN-10: 2200019858, Paris, France. 320 pp. 
HAASNOOT, M.; MIDDELKOOP H., VAN BEEK E.; VAN DEURSEN, W. P. A. (2011) A method to develop sustainable water management strategies for an uncertain future. Sustainable Development 19, 369-381.

HOWLETT, M. \& RAMESH, M. (2003). Studying Public Policy - Policy Cycles and Policy SubSystems. Oxford Univ. Press, Oxford (UK), ISBN-10: 0-19-541794-1, 311 pp.

HUITEMA, D.; MOSTERT, E.; EGAS, W.; MOELLENKAMP, S.; PAHL-WOSTL, C.; YALCIN, R. (2009) Adaptive water governance: assessing the institutional prescriptions of adaptive (co-)management from a governance perspective and defining a research agenda. Ecology and Society 14(1), 26. Disponível em: http://www.ecologyandsociety.org/vol14/iss1/art26/

LAFITTE, J.-J.; DEVOS, P.; PORTET, P. (2008) Les organismes uniques d'irrigation. Ministère de l'écologie, de l'énergie, du développement durable et de l'aménagement du territoire - Ministère de l'agriculture et de la pêche. Rap. Oct. 2008, La Documentation Française, 78 pp.

LASOTA, A.; MACKEY, M. C. (1994) Chaos, Fractals and Noise. Springer Verlag, Berlin (Germany), ISBN 0387940 499, 472 pp.

MAKROPOULOS, C. K.; MEMON, F. A.; SHIRLEYSMITH C.; BUTLER, D. (2008) Futures: an exploration of scenarios for sustainable urban water management. Water Policy, 10 (4), 345-373.

MARCH, H., OLIVIER THEROND, O.; LEENHARDT, D. (2012) Water futures: Reviewing water-scenario analyses through an original interpretative framework. Ecological Economics, 82, 126-137.

MCINTOSH, B. S.; SEATON, R. A. F.; JEFFREY P. (2007) Tools to think with? Towards understanding the use of computer-based support tools in policy relevant research. Env. Modelling \& Software, 22: 640-648.

MERTON, R. K. (1936) The unanticipated consequences of purposive social action. American Sociological Review, 1(6), 894-904. 2012.

MICA, A.; PEISERT, A.; WINCZOREK JAN, J. (eds), (2011), Sociology and the Unintended. Robert Merton Revisited, Peter Lang, Frankfurt am Main (Germany), ISBN 978-3-631-62120-2, 387 pp.
MOGLIA, M.; PEREZ, P.; BURN, S. 2008. Urbanization and Water Development in the Pacific Islands. Development, 51, 49-55.

OMG - Object Management Group (2005) UML 2.0 Specification, August 2005. Disponível em: http://www.omg.org

OMG - Object Management Group (2010) Object constraint language. OMG formally released versions of OCL, version 2.2, February 2010. Disponível em: http://www.omg.org/spec/OCL/

PIYATHAMRONGCHAI, K.; BATTY, M. (2007) Integrating Cellular Automata and Regional Dynamics Using Gis; In Modelling Land-Use Change, E. Koomen, J. Stillwell, A. Bakema, H.J. Scholten eds., ISBN: 978-1-4020-6484-5, 259-279.

REYNAUD, A.; LEENHARD, D. (2008) MoGIRE: A Model for integrated water management. Proc. Intern. Congress on Env. Modelling and Software (iEMSs 2008). Barcelona, Catalonia, July 2008. M. Sanchez-Marre, J. B'ejar, J. Comas, A. Rizzoli \& G. Guariso (Eds.), ISBN: 978-84-7653-074-0. Disponível em: http://www.iemss.org/iemss2008/ index.php?n=Main.Proceedings

TAILLANDIER, P.; THEROND, O.; GAUDOU B. (2012) A new BDI agent architecture based on the belief theory. Application to the modeling of cropping plan decision-making. iEMSs - Int. Cong. Env. Modelling \& Software Managing Res. of a Limited Planet, 6th Bien. Meeting, Leipzig, Germany. R. Seppelt, A. A. Voinov, S. Lange, D. Bankamp (Eds.). Disponível em: http://www.iemss.org/society/index.php/ iemss-2012-proceedings

TESFATSION, L.; JUDD, K. L. (Eds.) (2006) Handbook of Computational Economics, Volume 2: Agent-Based Computational Economics. Handbooks in Economics Series, NorthHolland/Elsevier, Amsterdam (the Netherlands) ISBN-13: 978-0444512536, 904 pp.

TREUIL, J. P.; DROGOUL, A.; ZUCKER, J.-D. (2008) Modélisation et Simulation à Base d'Agents. Dunod / IRD, Paris (France), ISBN-13: 978-2100502165, $322 \mathrm{pp}$. 